\title{
URBAN TRANSPORT SYSTEM ANALYSIS
}

\author{
MARWA ABOUHASSAN \\ Assistant Professor, Architecture Department, College of Architecture and Design, Effat University, Saudi Arabia
}

\begin{abstract}
City center is exposed to many problems including the mixing uses, bottleneck in traffic and the inadequacy of the existing fabric for the current changes in the means of movement, therefore this paper studies the impact of the urban transportation system on the road network in the city center, in order to achieve a better environment. The paper focuses on analysis of the study area by making a comprehensive survey of quantification of trips generation as a result of these uses, and a survey of all the numbers of transport means and distribution to all regions of the study area, then the stage of traffic assignment to evaluate network connections to know the traffic level of service. Followed by a proposal for some alternatives can be applied to measure the impact on the road network as a result of buildings uses change and means of transport in the region. The paper is ended by recommendations that help to achieve the required balance resulting from the interactions between these uses and transport systems on the road network in the city center to reduce the pressure on them.
\end{abstract}

Keywords: city center, transport system, road network, buildings uses, urban transportation.

\section{INTRODUCTION}

Planning for sustainable land use and transport requires an integrated view of the two-way interaction between land use and transport. The challenges that cities are facing can no longer be dealt within the limited view of a single profession.

An interdisciplinary approach is needed which integrates land use policies with transport infrastructure development and traffic operation, as well as soft policies working with information or incentives. Only this integration will lead to a new, more balanced view of the entire urban planning process.

\section{PROBLEM DEFINITION}

The cities affected by the industrial revolution with the beginning of the nineteenth century and resulted in the proliferation of means of transportation and the multiplicity of ways of production and inflation in the number of population, which led to the inflation of cities, and the heart of the city areas most affected by this, which can be summarized as the following points:

- $\quad$ Mixing and overlapping uses.

- Opposes the bottleneck in the movement.

- Inadequacy of the existing fabric of the current changes in the modes of movement and communication.

\section{THE GOAL OF THE RESEARCH}

The study aims to achieve the desired results from the mutual interactions between land uses and traffic on the road network in the city center to reduce the pressure and achieve the balance.

In order to achieve this goal, it is a must to achieve several other objectives, including:

- Identify the trip rates from various districts of the city to the city center as a result of land use. 
- Evaluate the proper distribution of land uses, which achieves the highest efficiency of the traffic in the city center.

- $\quad$ Evaluate the efficiency of transportation systems used and proposed [1].

\section{CASE STUDY}

The case study is in the North-West part of the old city center of Alexandria city, Egypt $\left(0.68 \mathrm{KM}^{2)}\right.$, this area was chosen to be as a detailed study because of its special importance: Moral importance:

- It is the node of the old city center and the part which is representing all the city.

- The area has a historical dimension because it contains many historical buildings have symbolic values reflect the spirit of the city.

Functional importance:

- This is the heart of the city containing many different functions and special activities.

- The node of the movement and communication.

- It is very important area for economic transactions [2].

5 ANALYSIS OF THE CURRENT STUDY AREA

The study area was analyzed as shown in Fig. 2.
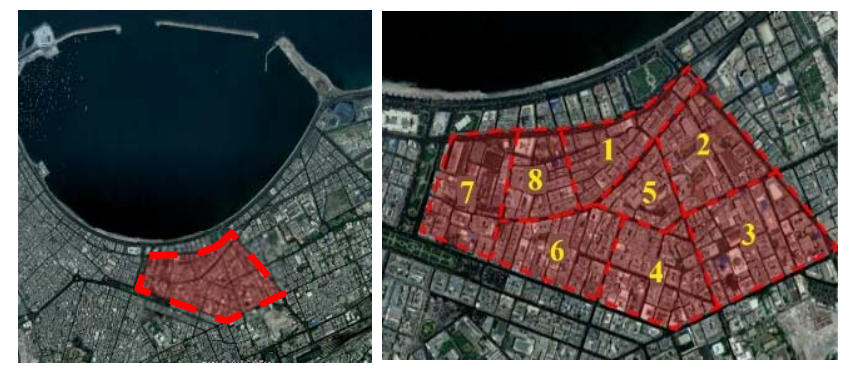

Figure 1: Case study area. (Source: Author.)

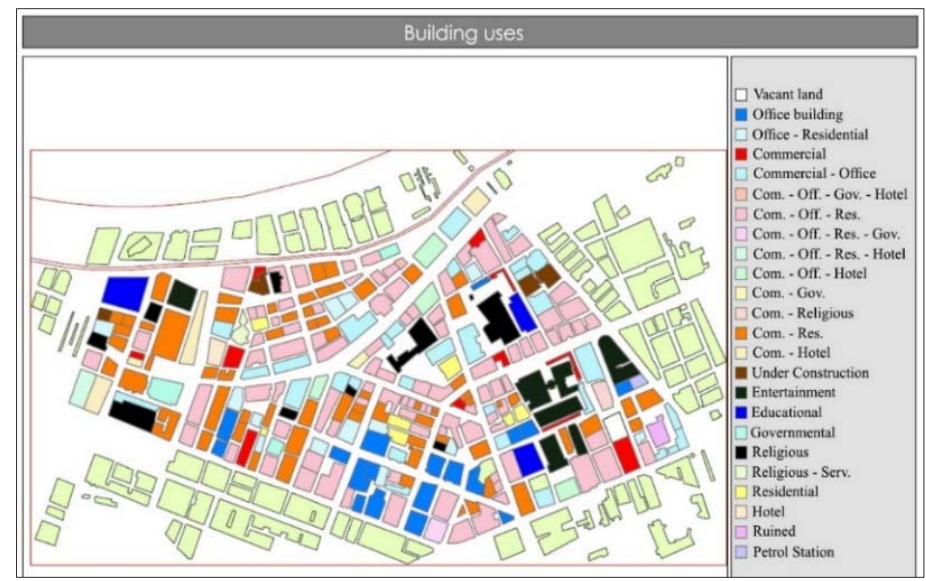

Figure 2: Buildings uses survey. (Source: Author.) 


\subsection{Building uses survey}

See Fig. 3.

\subsection{Trip generation rates resulting from the building uses}

From the previous building uses analysis the research calculated the traffic trip rates coming from the area of the uses by $\mathrm{m}^{2}$ in each part in the case study [3].

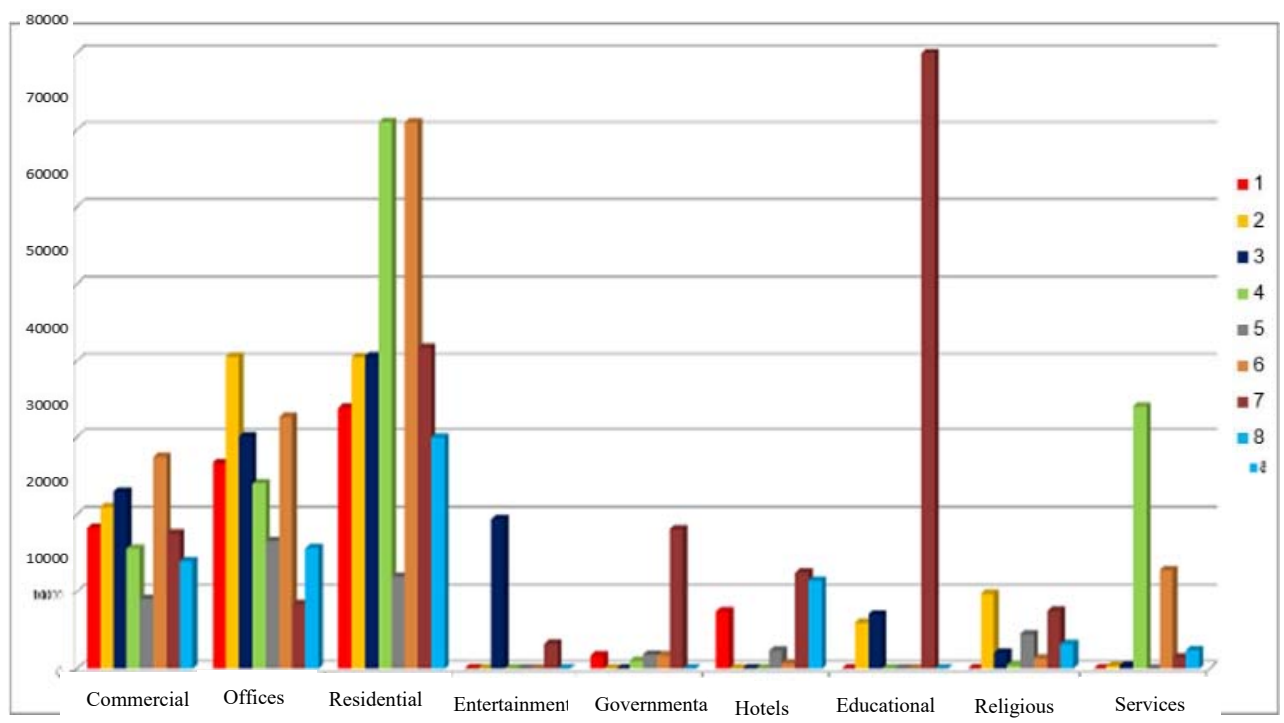

Figure 3: Total areas of building use in the study area. (Source: Author.)

Table 1: Trip generation rates in part 1. (Source: Author.)

\begin{tabular}{|c|c|c|c|c|c|c|c|c|c|c|}
\hline $\begin{array}{l}\text { OUT } \\
\text { TRIP }\end{array}$ & IN TRIP & OUT \% & IN \% & trip rates & RATE & Unit No. & Unit & Area S.F. & Area m2 & 1 \\
\hline 3459.31 & 3323.651 & $51 \%$ & $49 \%$ & 6782.962 & 34.57 & 196.2095 & 1000 S.F. & 196209.5 & 18228.31 & Comm. \\
\hline 355.0204 & \begin{tabular}{|l|}
72.71503 \\
\end{tabular} & $83 \%$ & $17 \%$ & \begin{tabular}{|l|}
427.7354 \\
\end{tabular} & 1.49 & 287.0708 & 1000 S.F. & 287070.8 & 26669.53 & Offit. \\
\hline 39.277 & \begin{tabular}{|l|}
72.943 \\
\end{tabular} & $35 \%$ & $65 \%$ & \begin{tabular}{|r|}
112.22 \\
\end{tabular} & 0.62 & 181 & unit & 363864.9 & 33803.87 & Res. \\
\hline 0 & 0 & $36 \%$ & $64 \%$ & 0 & 4.91 & 0 & 1000 S.F. & 0 & 0 & Ent. \\
\hline 15.40115 & 6.919356 & $69 \%$ & $31 \%$ & 22.3205 & 1.21 & 18.4467 & 1000 S.F. & 18446.7 & 1713.74 & Gov. \\
\hline 31.3349 & 35.3351 & $47 \%$ & $53 \%$ & 66.67 & 0.59 & 113 & Room & 80100.09 & 7441.48 & Hot. \\
\hline 0 & 0 & $55 \%$ & $45 \%$ & 0 & 1.21 & 0 & 1000 S.F. & 0 & 0 & Edu. \\
\hline 0 & 0 & $52 \%$ & $48 \%$ & 0 & 0.55 & 0 & 1000 S.F. & 0 & 0 & $\operatorname{Rel}$ \\
\hline 0 & 0 & $56 \%$ & $44 \%$ & 0 & 13.94 & 0 & 1000 S.F. & 0 & 0 & Ser. \\
\hline 3900.344 & 3511.564 & & & 7411.907 & & & & & & \\
\hline
\end{tabular}


Table 2: Trip generation rates in the study area. (Source: Author.)

\begin{tabular}{|c|c|c|c|c|c|c|c|c|c|c|c|c|c|c|c|}
\hline & $\% \mathbb{N}$ & $\begin{array}{l}\text { OUT } \\
\text { TRRP }\end{array}$ & $\mathbb{N} \mathbb{N} \mathbb{R} P$ & $\%$ & $\begin{array}{l}\text { Total } \\
\text { Trips } \\
\end{array}$ & $\begin{array}{l}\text { Ser. Area } \\
\text { m2 }\end{array}$ & $\begin{array}{c}\text { Rel. Area } \\
\text { m2 }\end{array}$ & $\begin{array}{c}\text { Eduu. Area } \\
\text { m2 }\end{array}$ & $\begin{array}{c}\text { Hotel Area } \\
\text { m2 }\end{array}$ & $\begin{array}{c}\text { Gov. Area } \\
\text { m2 } \\
\end{array}$ & $\begin{array}{c}\text { Ent. Area } \\
\text { m2 }\end{array}$ & $\begin{array}{c}\text { Res. Area } \\
\text { m2 }\end{array}$ & $\begin{array}{c}\text { Off. Area } \\
\text { m2 }\end{array}$ & $\begin{array}{c}\text { Comm. Area } \\
\text { m2 }\end{array}$ & \\
\hline 10.7 & 10.7 & 3900.3 & 3511.6 & 10 & 7411.9 & 0.0 & 0.0 & 0.0 & 7441.5 & 1713.7 & & 33803.9 & 26669.5 & 18228.3 & \\
\hline 12.9 & 12 & 4665.5 & & & 8769.3 & & 752.4 & & & & & & & & \\
\hline 14.5 & 15 & 5276.7 & 5098.6 & & 10375.3 & & & & & 0.0 & 19324.6 & & 149 & & \\
\hline 17.1 & 16.1 & 6212.4 & 5292.1 & & 11504.5 & & & & & 70. & & 10944.0 & 23948.5 & 55 & \\
\hline 5.5 & 5.4 & 2002.4 & 60.9 & 4 & 3763.3 & 0.0 & & & 200 & 1872.7 & & 11955.5 & 1,9 & & \\
\hline 18.8 & 18.5 & 6804.0 & \begin{tabular}{|l|l|} 
& 6083.2 \\
\end{tabular} & 18.7 & 12887.3 & 39.1 & 711.2 & 0.0 & 745.7 & 1724.7 & 0.0 & 0919.8 & \begin{tabular}{|l|}
32577.2 \\
\end{tabular} & 402.4 & \\
\hline 11.8 & 12.5 & 4287.4 & 4111.0 & 12.2 & 8398.4 & & 7484.1 & 944.0 & 2446.1 & 18090.0 & 3208.1 & & 8335.4 & 7528.9 & \\
\hline 8.6 & 8.7 & 3133.9 & 2854.7 & 8.7 & 5988.6 & 1.8 & 3162.5 & 0 & 11437.1. & 0.0 & 0.0 & 29942.6 & 15599.2 & 3858.0 & \\
\hline 100.0 & 100.0 & 36282.8 & & & 69098.7 & 51395.3 & 28876. & 92960.7 & 34390.8 & 24471.2 & 22532.7 & 340387.0 & 194441.9 & 145619.7. & \\
\hline
\end{tabular}

After that, the research put all the trip rates from the 8 parts in the case study in one schedule to calculate the total trip rates in the study area.

\subsection{Analysis of the transportation modes numbers in the study area}

Table 3 shows the number of the main transportation modes in different points in the case study.

Table 3: Transportation modes No. in the study area. (Source: Author.)

\begin{tabular}{|c|c|c|c|c|c|c|c|}
\hline Total & Serv. & bus & $\begin{array}{c}\text { Micro } \\
\text { bus }\end{array}$ & Taxi & Private & hour & $\begin{array}{c}\text { Point } \\
\text { No. }\end{array}$ \\
\hline 2976.9 & 138 & 20 & 32 & 1468 & 1242 & $9 \rightarrow 10$ & \multirow{3}{*}{1} \\
\hline 2109.5 & 114 & 64 & 50 & 612 & 1142 & $2 \rightarrow 3$ & \\
\hline 1830.3 & 62 & 18 & 24 & 604 & 1072 & $5 \rightarrow 6$ & \\
\hline 1180.4 & 18 & 1 & 7 & 679 & 465 & $9 \rightarrow 10$ & \multirow{2}{*}{2} \\
\hline 750.5 & 30 & 11 & 10 & 352 & 322 & $5 \rightarrow 6$ & \\
\hline 1170 & 60 & 30 & 70 & 430 & 486 & $12 \rightarrow 1$ & 3 \\
\hline 1989 & 96 & 56 & 90 & 814 & 790 & $9 \rightarrow 10$ & \multirow{2}{*}{4} \\
\hline 1260.7 & 150 & 28 & 56 & 362 & 560 & $6 \rightarrow 7$ & \\
\hline 711.9 & 36 & 3 & 27 & 395 & 220 & $9 \rightarrow 10$ & \multirow{3}{*}{5} \\
\hline 619.8 & 72 & 0 & 14 & 200 & 306 & $12 \rightarrow 1$ & \\
\hline 517 & 32 & 0 & 10 & 150 & 310 & $4 \rightarrow 5$ & \\
\hline 1467.3 & 150 & 0 & 234 & 412 & 470 & $11 \rightarrow 12$ & \multirow{4}{*}{6} \\
\hline 1503 & 120 & 30 & 230 & 406 & 496 & $11 \rightarrow 12$ & \\
\hline 1037.3 & 102 & 0 & 134 & 312 & 370 & $5 \rightarrow 6$ & \\
\hline 1158.3 & 90 & 24 & 174 & 306 & 396 & $5 \rightarrow 6$ & \\
\hline 1289.6 & 24 & 1 & 8 & 884 & 360 & $9 \rightarrow 10$ & \multirow{3}{*}{7} \\
\hline 1729.1 & 30 & 1 & 18 & 864 & 795 & $12 \rightarrow 1$ & \\
\hline 1556.2 & 60 & 15 & 6 & 441 & 1000 & $4 \rightarrow 5$ & \\
\hline 458.1 & 6 & 0 & 18 & 258 & 162 & $9 \rightarrow 10$ & \multirow{3}{*}{8} \\
\hline 559.9 & 6 & 8 & 12 & 198 & 318 & $12 \rightarrow 1$ & \\
\hline 515.5 & 20 & 5 & 5 & 100 & 372 & $4 \rightarrow 5$ & \\
\hline 2168.9 & 78 & 8 & 2 & 942 & 1110 & $10 \rightarrow 11$ & \multirow{3}{*}{9} \\
\hline 2055 & 60 & 0 & 0 & 984 & 996 & $12 \rightarrow 1$ & \\
\hline 1643 & 36 & 4 & 0 & 744 & 846 & $6 \rightarrow 7$ & \\
\hline 1660 & 72 & 8 & 0 & 672 & 882 & $11 \rightarrow 12$ & \multirow{2}{*}{10} \\
\hline 1143 & 60 & 0 & 0 & 402 & 666 & $5 \rightarrow 6$ & \\
\hline 1134.5 & 30 & 0 & 10 & 498 & 582 & $10 \rightarrow 11$ & 11 \\
\hline 212.25 & 5 & 4 & 0 & 90 & 108 & $9 \rightarrow 10$ & 12 \\
\hline 537 & 36 & 0 & 0 & 252 & 240 & $9 \rightarrow 10$ & \multirow{2}{*}{13} \\
\hline 579 & 36 & 0 & 0 & 318 & 216 & $9 \rightarrow 10$ & \\
\hline 161.65 & 5 & 1 & 2 & 48 & 102 & $9 \rightarrow 10$ & 14 \\
\hline 1680 & 48 & 3 & 0 & 960 & 654 & $9 \rightarrow 10$ & 15 \\
\hline 641.3 & 18 & 1 & 24 & 396 & 180 & $9 \rightarrow 10$ & 16 \\
\hline 238.8 & 24 & 0 & 24 & 30 & 138 & $9 \rightarrow 10$ & 17 \\
\hline
\end{tabular}




\subsection{Traffic assignment on road network}

This stage is the signing of trips size each way on the links of the proposed transport network, therefore can see the volume of traffic on each link in the network, using the program (Assign 14) to do this customization. Evaluate network connections to know the level of traffic service, the value of (volume/capacity) [4].

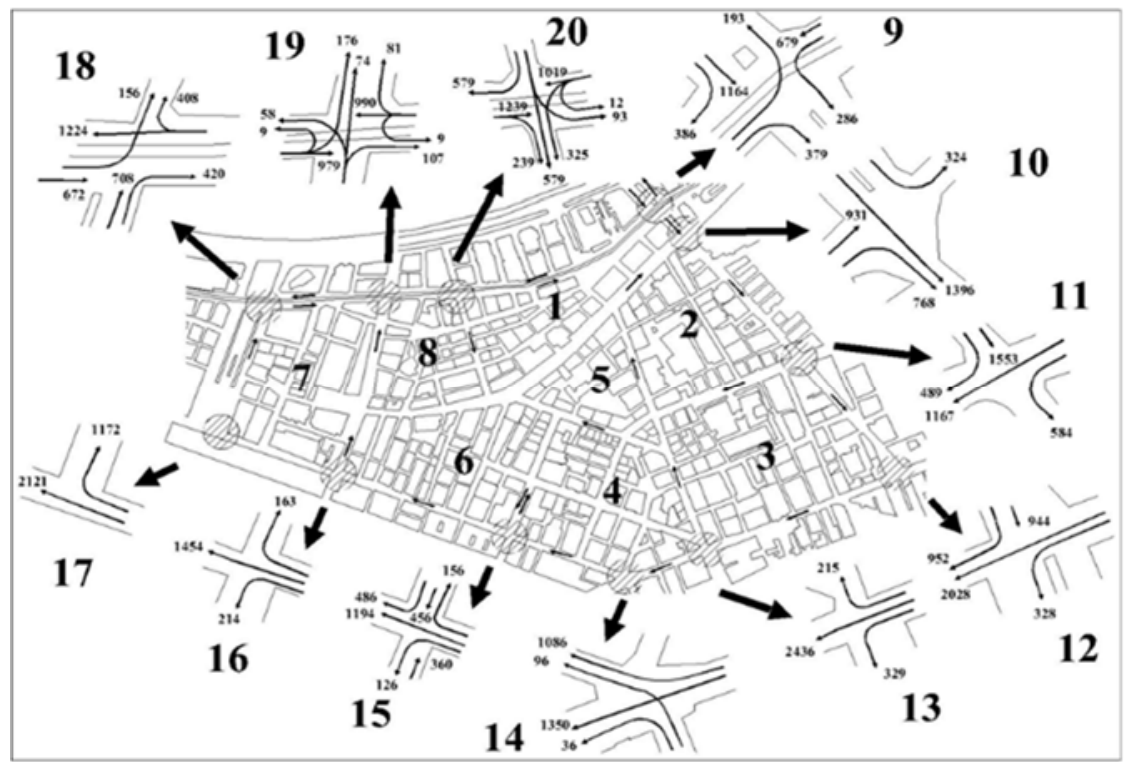

Figure 4: In and out trips in the main intersection points of the streets in the study area. (Source: Author.)

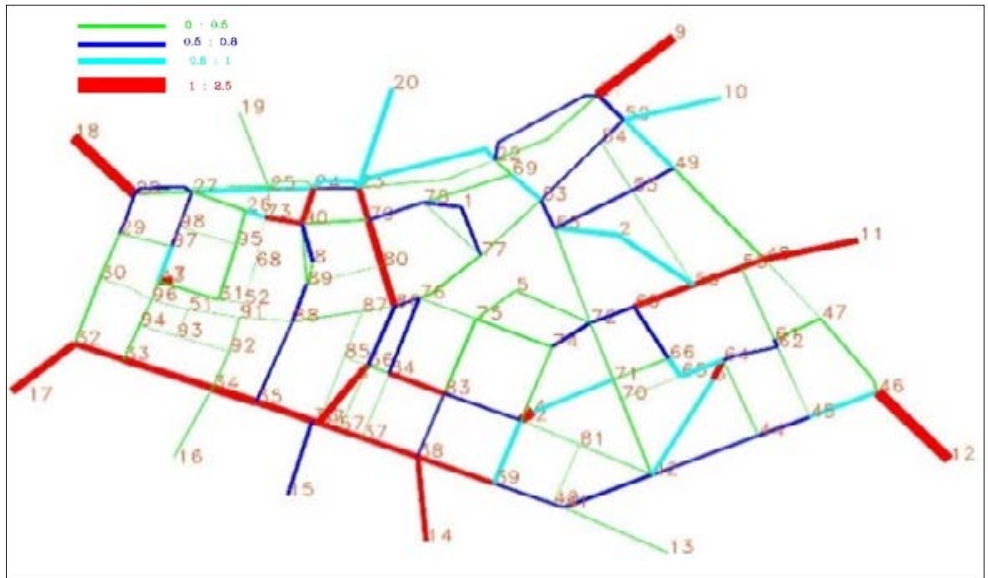

Figure 5: Current traffic Assignment. Show the volume of traffic on each link in the network. (Source: Author.) 


\section{FIRST PROPOSED ALTERNATIVE: THE IMPACT OF CHANGING BUILDINGS USES ON THE ROAD NETWORK}

Increase office buildings and minimize housing in bad buildings for District No. 7, because this area is located on the main traffic hubs and next to places can be as a parking, either in the rest of the areas will increase housing, while maintaining the same total area for each use, as in Current situation.

\section{INCREASING PUBLIC TRANSPORT ON THE ROAD NETWORK}

7.1 Prevent the passage of private vehicles and provide parking areas

Prevent private cars in the internal streets of the city center at certain hours of the day and allow it only in the ring-road which surrounds the study area. Select parking areas places near the public transport stations to encourage citizens to leave their private cars and use public transportation [5].

Table 4: Trip generation rates depending on the proposed use. (Source: Author.)

\begin{tabular}{|c|c|c|c|c|c|c|c|c|c|c|c|c|c|c|c|}
\hline$\%$ OUT & $\% \mathbb{I N}$ & $\begin{array}{l}\text { OUT } \\
\text { TRIP }\end{array}$ & IN TRIP & $\%$ & $\begin{array}{l}\text { total } \\
\text { trips }\end{array}$ & Ser. Area & Rel. area & $\begin{array}{l}\text { Edu. } \\
\text { Area }\end{array}$ & Hot. Area & $\begin{array}{l}\text { Gov. } \\
\text { area }\end{array}$ & Ent. Area & $\begin{array}{l}\text { Res. } \\
\text { Area }\end{array}$ & Off. Area & $\begin{array}{l}\text { Comm. } \\
\text { Area }\end{array}$ & \\
\hline 10.6672 & \begin{tabular}{|l|l|}
10.72089 \\
\end{tabular} & 3881.234 & 3520.199 & 10.69267 & 7401.434 & 0 & 0 & 0 & \begin{tabular}{|l|l|}
7441.48 \\
\end{tabular} & 1713.74 & & 40325.24 & 24663.46 & 18228.31 & \\
\hline 12.74903 & 12.75848 & \begin{tabular}{|l|}
4638.702 \\
\end{tabular} & 4189.242 & 12.75351 & \begin{tabular}{|l}
8827.944 \\
\end{tabular} & 336.54 & 9752.4 & 5988.56 & 0 & 0 & & 42809.23 & 29761.99 & 21562.46 & \\
\hline 14.39274 & 15.5477 & 5236.762 & 5105.082 & 14.94061 & 10341.84 & 455.96 & 2060.4 & 7028.12 & & 0 & 19324.6 & 47651.64 & 26478.56 & 22982.23 & \\
\hline 16.95919 & 16.08271 & 6170.56 & 5280.751 & 16.54342 & 11451.31 & 33962.91 & 525.48 & 0 & 0 & 1070.1 & & 68426.97 & 20842.82 & 15564.69 & \\
\hline 5.440123 & 5.394452 & \begin{tabular}{|l|l|}
1979.375 \\
\end{tabular} & 1771.266 & 5.418459 & 3750.641 & 0 & 4520.04 & 0 & 2320.38 & 1872.72 & & 20302.18 & 14172.1 & 9107.28 & \\
\hline 18.46326 & 18.44129 & \begin{tabular}{|l|l|}
6717.812 \\
\end{tabular} & \begin{tabular}{|l|}
6055.19 \\
\end{tabular} & 18.45284 & 12773 & 12739.1 & 1371.16 & 0 & 745.65 & 1724.67 & & 65072.91 & 26573.18 & 27402.38 & \\
\hline 12.71717 & \begin{tabular}{|l|l|}
12.35882 \\
\end{tabular} & 4627.111 & 4058.015 & 12.54719 & 8685.126 & 1448.92 & 7484.14 & 79944 & 12446.14 & 18090 & & 26866.26 & 39643.54 & 17528.85 & 7 \\
\hline 8.611276 & 8.69566 & 3133.191 & 2855.217 & 8.651305 & 5988.408 & 2451.84 & 3162.46 & 0 & \begin{tabular}{|l|l|}
11437.14 \\
\end{tabular} & 0 & & 30207.26 & \begin{tabular}{|l|l|}
15510.99 \\
\end{tabular} & 13858.04 & 8 \\
\hline 100 & 100 & 36384.75 & 32834.96 & 100 & 69219.71 & 51395.27 & 28876.08 & 92960.68 & 34390.79 & 24471.23 & 19324.6 & 341661.7 & 197646.6 & 146234.2 & \\
\hline
\end{tabular}

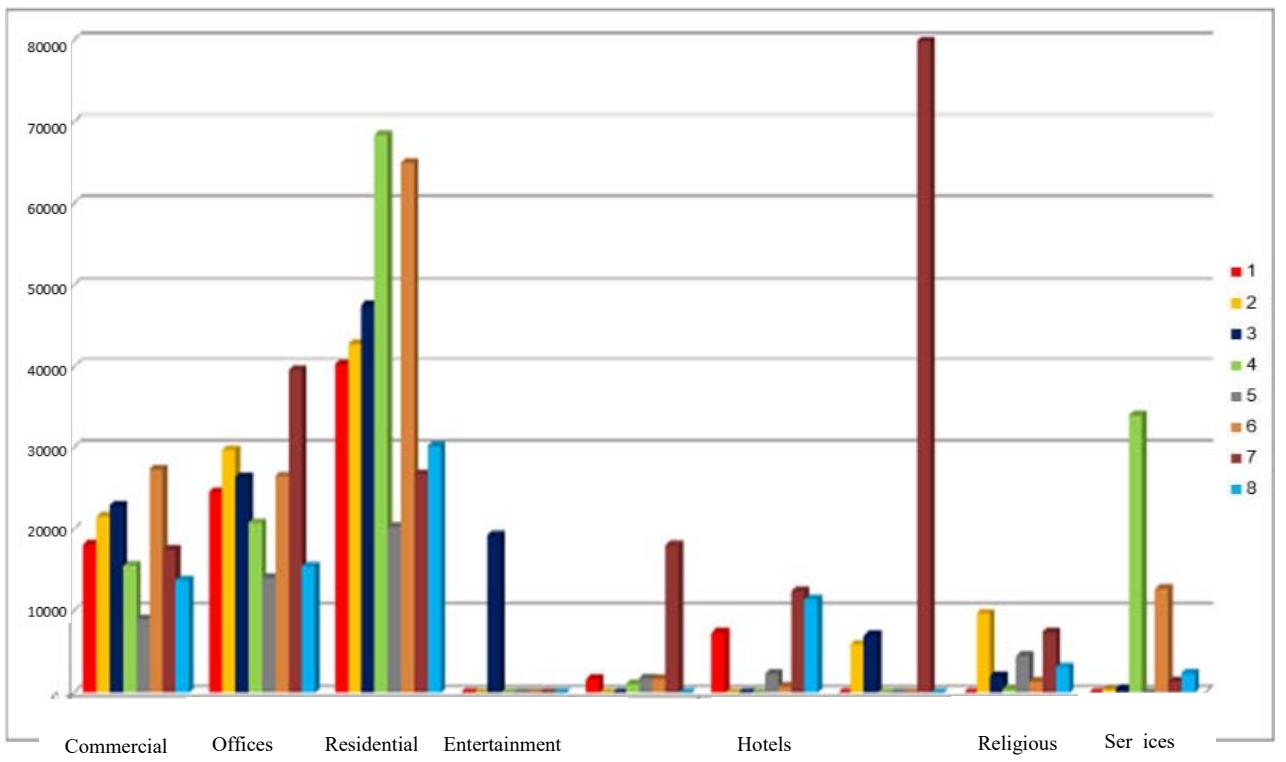

Figure 6: Total areas of building uses depending on the proposed use. (Source: Author.) 


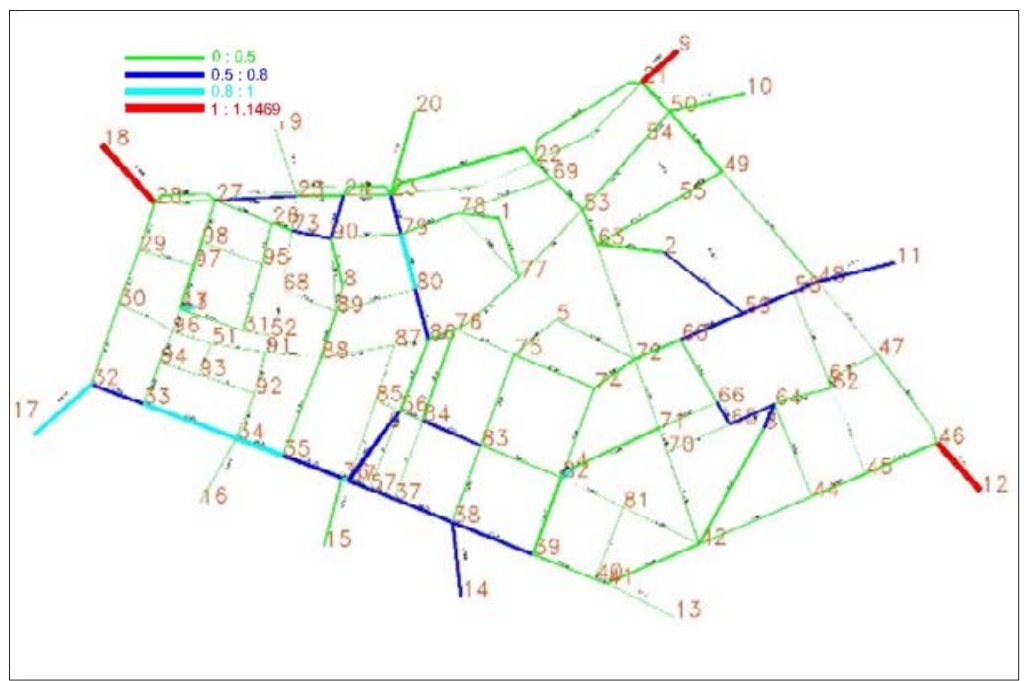

Figure 7: Traffic Assignment on road network depending on the proposed use. This minimizes the problems in the connections. (Source: Author.)

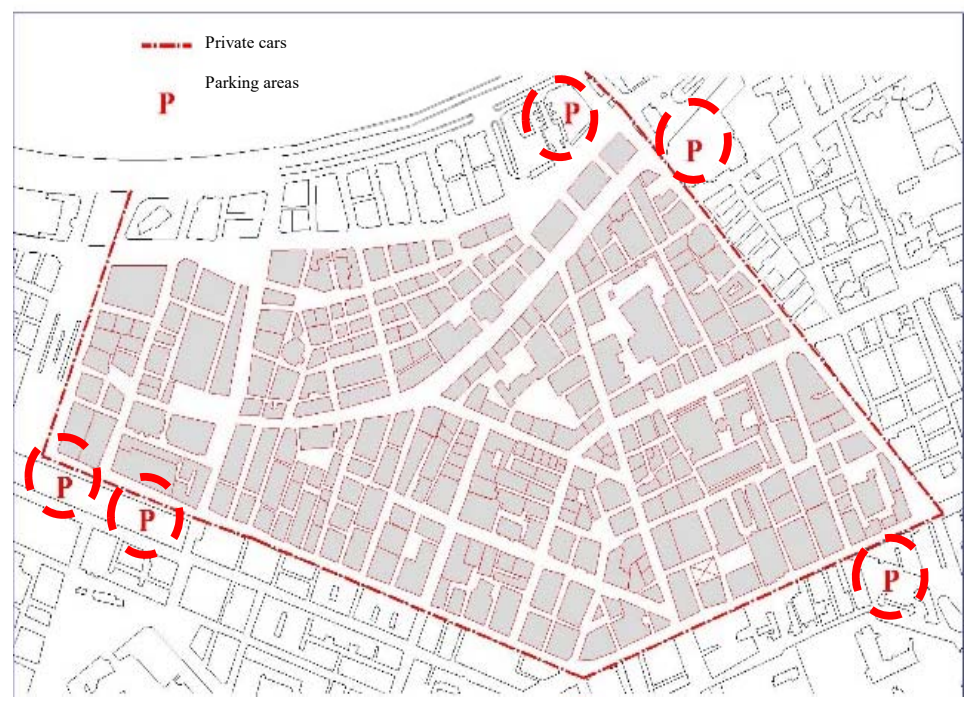

Figure 8: Roads for private cars and parking areas. (Source: Author.)

\subsection{Increase public transport systems}

Buses: Give priority to public buses on the roads and allocate a fixed path to use it.

Electric car: Provides a high-level and environmentally friendly system. It is small in size, do not take a big space and save time in searching for the traditional position of the car, especially in the city center [6]. 
Tram: It is one of the most important means of transport that can accommodate a large number of passengers, therefore it is very important develop the tram path and the stations to provide passenger comfort and quick accessibility [7].

Bikes: Providing many of the bikes that operate by rental system, this system helps to reduce traffic congestion and purify the city's air. It is a must to ensure the safe ways for bicycles, through the re-planning of road networks.

Street design: Increasing public transport systems in the road network in the study area need to have a good design to the streets with separate lanes for cars, buses, bikes, tram and pedestrian. Also choosing a best location for pedestrian crossing [8].

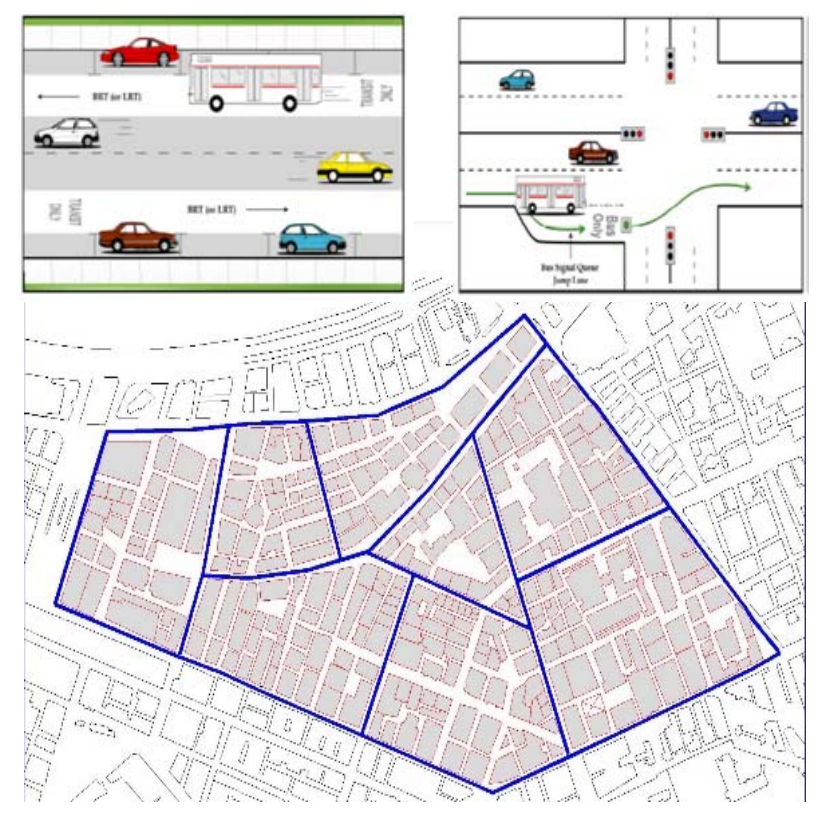

Figure 9: Increase public buses in certain roads. (Source: Author).

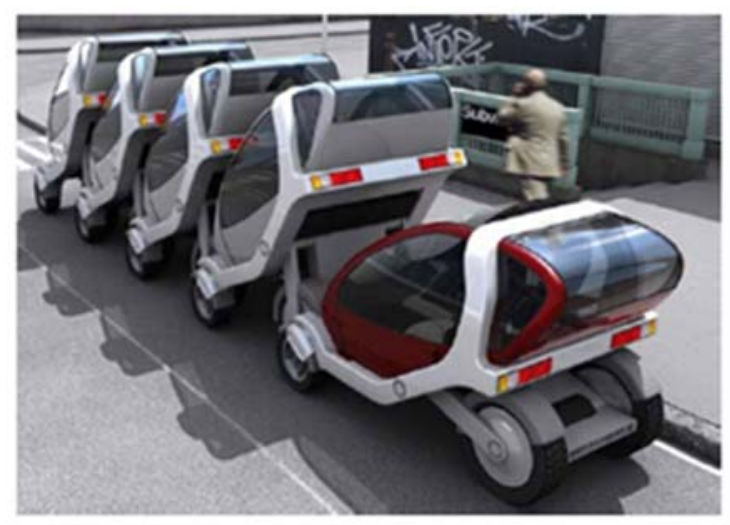

Figure 10: Using environmental electric car in internal streets of the study area. (Source: Inderwildi \& David, 2012.) 

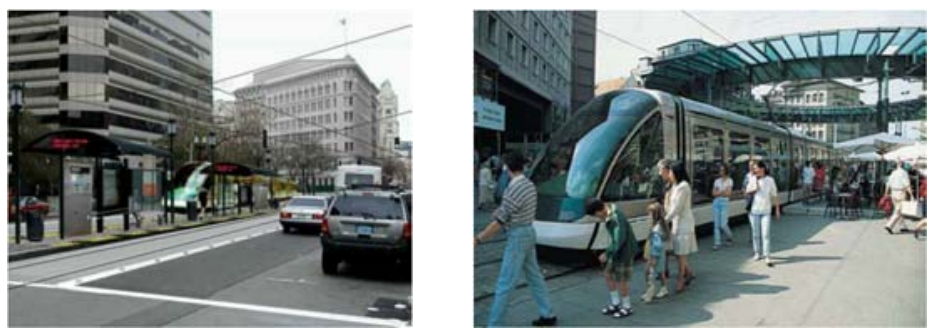

Figure 11: Develop tram path and the stations. (Source: Suzuki \& Luchi, 2013.)
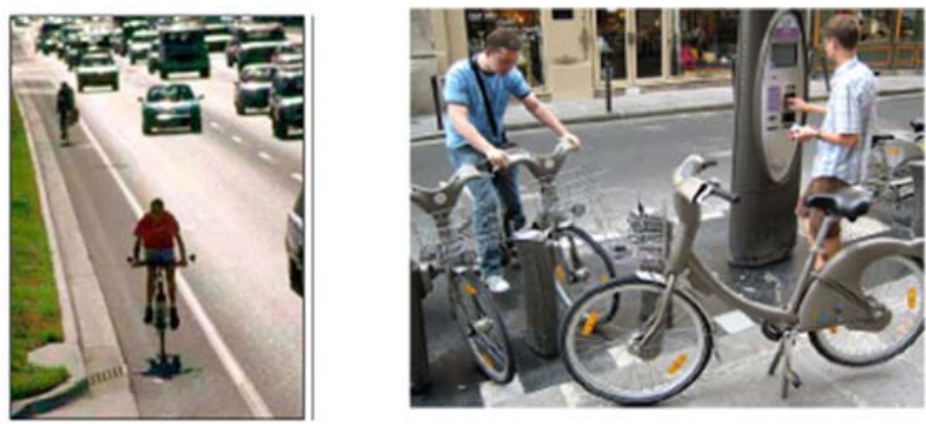

Figure 12: Provide lanes for bikes. (Source: Suzuki \& Luchi, 2013.)

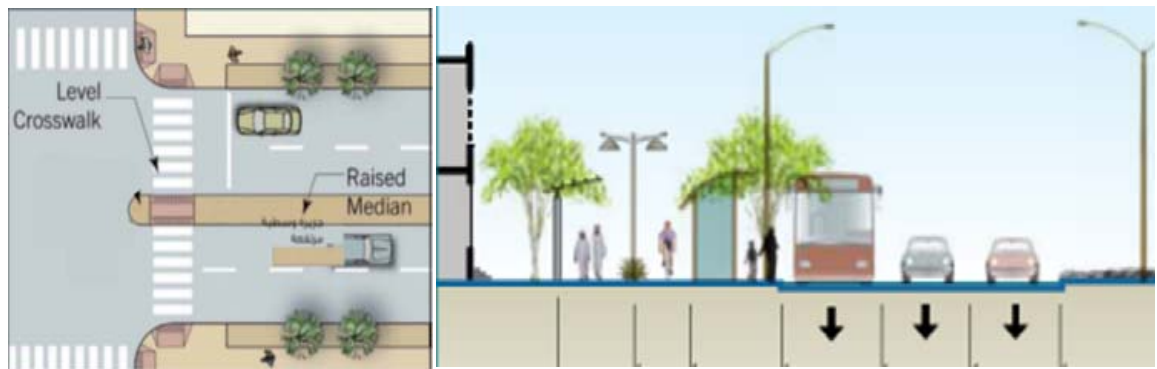

Figure 13: Street Design. (Source: Golem \& Smith, 2010.)

\section{SECOND PROPOSED ALTERNATIVE: THE IMPACT OF INCREASING PUBLIC TRANSPORT ON THE ROAD NETWORK}

8.1 Stage of division of trips to various means of transport (Modal Split):

- Calculate numbers of transport means in the main intersection points of the streets in the study area, in the rush hour with classification into types of methods.

- Calculate the averages for all the points.

- $\quad$ Find a ride equivalent unit.

- Calculate the number of users for each type of transportation then transferred to percentage. 
- $\quad$ Propose new percentage of the number of users and therefore know the numbers of new users in the proposed situation.

- Calculate the new averages and find equivalent of the proposed riding unit.

- By knowing equivalent in the current situation and the proposed equivalent and rate used in the current situation thus find a rate that should be used in the proposed situation.

- Compensation occurs in the following tables to calculate the number of trips in and out of each region of the study area as a result of the proposed situation.

- Calculate OD of the proposed situation and applied to the assignment program to see impact on the road network [4].

Table 5: Proposed modal split. (Source: Author)

\begin{tabular}{|c|c|c|c|c|c|c|c|c|}
\hline Total & Tram & Serv. & Bus & Microbus & Taxi & Private & Pick hour & Point \\
\hline 2976.9 & 0 & 138 & 20 & 32 & 1468 & 1242 & $9 \rightarrow 10$ & \multirow{3}{*}{1} \\
\hline 2109.5 & 0 & 114 & 64 & 50 & 612 & 1142 & $2 \rightarrow 3$ & \\
\hline 1830.3 & 0 & 62 & 18 & 24 & 604 & 1072 & $5 \rightarrow 6$ & \\
\hline 1180.4 & 0 & 18 & 1 & 7 & 679 & 465 & $9 \rightarrow 10$ & \multirow{2}{*}{2} \\
\hline 750.5 & 0 & 30 & 11 & 10 & 352 & 322 & $5 \rightarrow 6$ & \\
\hline 1170 & 0 & 60 & 30 & 70 & 430 & 486 & $12 \rightarrow 1$ & 3 \\
\hline 1989 & 0 & 96 & 56 & 90 & 814 & 790 & $9 \rightarrow 10$ & \multirow[b]{2}{*}{4} \\
\hline 1260.7 & 0 & 150 & 28 & 56 & 362 & 560 & $6 \rightarrow 7$ & \\
\hline 711.9 & 0 & 36 & 3 & 27 & 395 & 220 & $9 \rightarrow 10$ & \multirow{3}{*}{5} \\
\hline 619.8 & 0 & 72 & 0 & 14 & 200 & 306 & $12 \rightarrow 1$ & \\
\hline 517 & 0 & 32 & 0 & 10 & 150 & 310 & $4 \rightarrow 5$ & \\
\hline 1467.3 & 4 & 150 & 0 & 234 & 412 & 470 & $11 \rightarrow 12$ & \multirow{4}{*}{6} \\
\hline 1503 & 5 & 120 & 30 & 230 & 406 & 496 & $11 \rightarrow 12$ & \\
\hline 1037.3 & 7 & 102 & 0 & 134 & 312 & 370 & $5 \rightarrow 6$ & \\
\hline 1158.3 & 5 & 90 & 24 & 174 & 306 & 396 & $5 \rightarrow 6$ & \\
\hline 1289.6 & 0 & 24 & 1 & 8 & 884 & 360 & $9 \rightarrow 10$ & \multirow{3}{*}{7} \\
\hline 1729.1 & 0 & 30 & 1 & 18 & 864 & 795 & $12 \rightarrow 1$ & \\
\hline 1556.2 & 0 & 60 & 15 & 6 & 441 & 1000 & $4 \rightarrow 5$ & \\
\hline 458.1 & 0 & 6 & 0 & 18 & 258 & 162 & $9 \rightarrow 10$ & \multirow{3}{*}{8} \\
\hline 559.9 & 0 & 6 & 8 & 12 & 198 & 318 & $12 \rightarrow 1$ & \\
\hline 515.5 & 0 & 20 & 5 & 5 & 100 & 372 & $4 \rightarrow 5$ & \\
\hline 2168.9 & 0 & 78 & 8 & 2 & 942 & 1110 & $10 \rightarrow 11$ & \multirow{3}{*}{9} \\
\hline 2055 & 0 & 60 & 0 & 0 & 984 & 996 & $12 \rightarrow 1$ & \\
\hline 1643 & 0 & 36 & 4 & 0 & 744 & 846 & $6 \rightarrow 7$ & \\
\hline 1660 & 0 & 72 & 8 & 0 & 672 & 882 & $11 \rightarrow 12$ & \multirow{2}{*}{10} \\
\hline 1143 & 0 & 60 & 0 & 0 & 402 & 666 & $5 \rightarrow 6$ & \\
\hline 1134.5 & 0 & 30 & 0 & 10 & 498 & 582 & $10 \rightarrow 11$ & 11 \\
\hline 212.25 & 0 & 5 & 4 & 0 & 90 & 108 & $9 \rightarrow 10$ & 12 \\
\hline 537 & 0 & 36 & 0 & 0 & 252 & 240 & $9 \rightarrow 10$ & \multirow{2}{*}{13} \\
\hline 579 & 0 & 36 & 0 & 0 & 318 & 216 & $9 \rightarrow 10$ & \\
\hline 161.65 & 0 & 5 & 1 & 2 & 48 & 102 & $9 \rightarrow 10$ & 14 \\
\hline 1680 & 0 & 48 & 3 & 0 & 960 & 654 & $9 \rightarrow 10$ & 15 \\
\hline 641.3 & 0 & 18 & 1 & 24 & 396 & 180 & $9 \rightarrow 10$ & 16 \\
\hline 238.8 & 0 & 24 & 0 & 24 & 30 & 138 & $9 \rightarrow 10$ & 17 \\
\hline & 5 & 56.6 & 10.1 & 38 & 487.7 & 540.4 & av. & \multirow{5}{*}{ 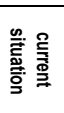 } \\
\hline 1203.65 & 20 & 70.75 & 20.2 & 64.6 & 487.7 & 540.4 & equivelant & \\
\hline 100 & 1.66 & 5.88 & 1.68 & 5.37 & 40.52 & 44.90 & $\%$ & \\
\hline 2501.35 & 260 & 56.6 & 262.6 & 380 & 731.55 & 810.6 & pers. & \\
\hline 100 & 10.39 & 2.26 & 10.50 & \begin{tabular}{|l|}
15.19 \\
\end{tabular} & \begin{tabular}{|l|}
29.25 \\
\end{tabular} & 32.41 & $\%$ & \\
\hline 100 & 15.39 & 2.26 & 22.91 & 20.19 & 39.25 & 0 & \%new & \multirow{4}{*}{ 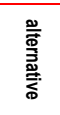 } \\
\hline 2501.438 & 385.07 & 56.60 & 573.02 & 505.07 & 981.69 & 0 & new pers. & \\
\hline 783.6026 & 7.405144 & 56.6 & 22.03914 & 50.50675 & 654.4567 & 0 & new av. & \\
\hline 884.767 & 29.62058 & 70.75 & 44.07827 & 85.86148 & 654.4567 & 0 & $\begin{array}{c}\text { new } \\
\text { equivelant }\end{array}$ & \\
\hline
\end{tabular}
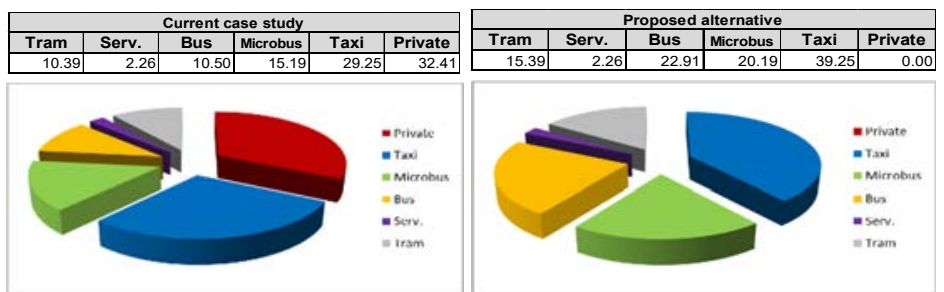

Figure 14: Percentage of users for each type of transportation modes. (Source: Author) 
8.2 Traffic assignment stage

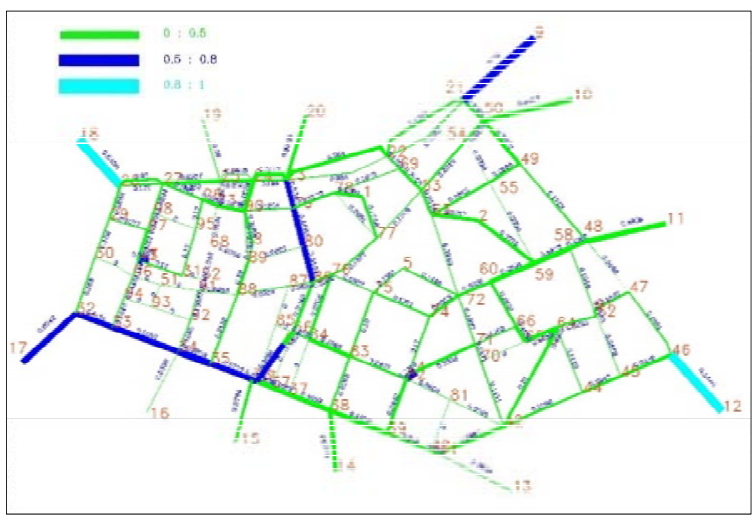

Figure 15: Proposed Traffic Assignment show the impact on the road network. (Source: Author.)

\section{CONCLUSIONS}

There is a relation between land use and road network. Any land use will attract trips from residents of the city and this applies when changing uses the trips are changing accordingly.

- Accessibility plays an important role in changing land use patterns and the higher degree of accessibility leads to higher value of the land.

- The absence of laws and legislation governing land use structure has contributed greatly to the deterioration of many of the central areas.

- Interfere a lot of activities in the city center of Alexandria affect the movement of internal traffic and road network.

- There is shortage in the current policies of transport within the cities, resulting large increase in the consumption of fuel and energy and the highest consumption rates come from using of the car as the primary means of transport and not focusing on public transport.

- Public transportation reduces traffic pressure on the road network.

- There are many parts of the road network in the current situation have bad level of service as the result of $\mathrm{v} / \mathrm{c}$ is greater than 1 and this shows the pressure on the existing road network.

\section{RECOMMENDATIONS}

Set land use regulations, which aim to reduce the use of the private cars and reduce conflict between different uses.

- Give license for establishing an activity after the study of its impact on traffic and noise level in the area.

- Commercial use preferred to be present on main roads network of the city center and reduces in the secondary roads to decrease the pressure and increase the level of service within it. 
- Administrative and service buildings when planning their places, it is preferred that be near to parking and public transport stations so users reduce the pressure on the internal roads of the city center network.

- The transportation must be planned according to stages and steps, including shortterm plans and long-term part of the overall development process of the state.

- Enhance traffic flow and thus relieve traffic congestion to reduce trip time and facilitate access to all land use and reducing different types of environmental pollution.

- Review traffic laws and analyze the strengths and weaknesses in order to develop them.

- $\quad$ Provide numbers of multi-story parking in the city center where the citizen leaves the car and uses means of public transport from the stations located near them and this can help to restore the importance of public transportation.

- Change the priorities of the street design of the current situation where the focus is on the movement of vehicles only to an integrated process that takes into account the needs of pedestrians, cyclists and public transport movement.

- $\quad$ Prevent private cars in the city center traffic at certain hours of the day.

- Providing many of the bikes that operate by subscription and rental system with saving their own stations, this system helps to reduce traffic congestion and purify the city's air.

- Provide high-level electric cars with environment-friendly system in the internal road network of the city center.

\section{REFERENCES}

[1] Hayashi, Y. \& Roy, J., Transport; Land-use and the Environment, Springer: London, 2013.

[2] Forster, E.M., Alexandria a History and Guide, TPP: London, 2014.

[3] San Diego Municipal Code, Trip Generation Manual, San Diego Municipal: San Diego, 2012.

[4] Patriksson, M., The Traffic Assignment Problem, Models \& Methods, Dover Publication Inc., New York, 2015.

[5] Garrett, M. Encyclopedia of Transportation, SAGE: London, 2014.

[6] Inderwildi, O. \& David, S., Energy, Tansport and Environment, Springer: London, 2012.

[7] Suzuki, H., Cervero, R. \& Luchi, K., Transforming Cities with Transit, The World Bank: Washington, DC, 2013.

[8] Golem, R. \& Smith, J., Relation Between Streetcars and the Built Environment, Transportation Research Board: Washington, DC, 2010. 